\title{
PROFESIONALIZACION Y EJERCICIO DE LA MEDICINA MEDIEVAL
}

\author{
Mercedes Gallent Marco \\ Universidad de Valencia
}

Se enclava y explica el presente trabajo dentro de nuestra investigación en torno a la Historia de la Sanidad del País Valenciano en la época medieval. Nuestra tesis doctoral constituyó una primera aportación al tema (1), sin duda un inicio o presentación más que una obra exhaustiva, desde una triple perspectiva: institucional (hospitales), epidemiológica y profesional.

La pretensión de nuestro estudio ha sido, por una parte, cubrir un flagrante hueco en la historiografía del país, puesto que salvo investigadores como Rodrigo Pertegás, Peset y Vidal, Cardoner i Planas o García Ballester, se ha marginado esta parcela de la Historia Social, cosa no ocurrida en otros ámbitos cronológicos o historiográficos.

Se justifica, además, la investigación emprendida sobre un ámbito tan específico, Historia de la Medicina (sanidad), como un afán de conectar con el grupo, bastante numeroso hoy en día, de estudiosos extranjeros que han dedicado un importante espacio de sus investigaciones a esta rama de la Historia (Historia Social), y como un intento de conocer el significado real de la incidencia social - fuerzas de producción- del binomio enfermedad/sociedad, entendido más como fenómeno socioeconómico que exclusivamente terapéutico:

¿La malalttia - subraya M. ${ }^{\text {a }}$ S. Mazzi-, ben al di là dall' essere un casuale e sfortunato evento strettamente privato $e$ individuale oppure una catastrofe collettiva, comúnque un fenomeno puramente biologico, diventa comprensibile se inserita nel mondo dei rapporti sociali. Essa ha strettamente a che fare con l'intreccio delle vicende economiche, sociali, politiche e culturali di un determinato popolo in un'epoca determinata" (2). 
Centraremos ahora nuestra atención en el análisis detallado de unas licencias médicas concedidas a ciudadanos del país pertenecientes al ámbito geográfico de Alicante. Por supuesto, no son documentos insignificantes, sino fuentes locuaces, denotativa o connotativamente, para la constatación de, al menos, tres puntos de carácter socio-institucional:

- El control político-profesional de médicos y cirujanos.

- La profesionalización y, a la vez, preocupación científica en el campo de la Medicina.

- El inicio de una conciencia de grupo-clase en la profesión médica, junto a una jerarquización en base a criterios científico-políticos.

1. Basamos el estudio en cuatro licencias procedentes del Archivo del Reino de Valencia (series de Real Chancillería y Manament y Empares - Justicia Civil-), concedidas por la autoridad real o por el Justicia Civil, tras el examen ante un «prothofisico» o «prothocirujano» real o ante los examinadores oficiales del municipio (3).

Los documentos, aunque constatan un objetivo común: reconocimiento de un status profesional, evidencian algunas diferencias que intentaremos hacer ver.

La elaboración del trabajo incluirá el análisis específico de las licencias y comparación de las mismas y una conclusión en torno a los tres puntos señalados en la introducción.

\subsection{Licencias concedidas por la autoridad real}

Los documentos que vamos a estudiar a continuación corresponden uno al año 1443, en que se autoriza a Johanne de Çamora, de Cocentayna, para ejercer la cirugía. Los dos restantes, fechados en 1445, se refieren a las licencias para ejercer la "phisica" concedida a Johanne Martí y la cirugía a Johanne González, ambos de Elche (4).

Su contenido es prácticamente idéntico, por lo cual creemos más operativo a nivel metodológico, describirlas indistintamente como una estructura similar.

Estos documentos comienzan con un preámbulo en el que se resalta la preocupación de la realeza por el bienestar físico de sus súbditos:

"Quemadmodum salutis tutelam corporum vicatis imperitis et temerariis remediis".

y la necesidad de proporcionarles profesionales cualificados:

«Procuramus sic experta et probata medicaminum ministeria curandorum languentium gratia promovemus».

A partir de aquí, se especifica claramente su objetivo: el permiso para ejercer una profesión médica a una determinada persona. 
Detallada, en primer lugar, la procedencia y, en un caso, la profesión de los aspirantes: "Johanem de Çamora ville de Cocentayna", "Johannem Marti habitatorem ville de Elig" y "Johannem Goçalvez barbitonsorem ville de Elig", introducen los datos personales-profesionales del examinador:

"Gabrielem Garcia magistrum in artibus et medicina fisicum et cirurgicum domus nostre mandato nostro examinatum» (5).

que se responsabiliza de la habilitación del candidato en el arte que desea ejercer: "phisica» o cirugía.

Superado el examen y siendo encontrados «idóneos y suficientes», la reina $D .{ }^{a}$ María, en virtud del criterio de su médico, les concede la posibilidad de practicar la "phisica" y la cirugía en un campo especificado claramente: tanto en las villas de donde proceden como en cualquier otra parte donde habiten:

"Concedimus et licentiam ac facultatem plenariam elargimur quod tam in dicta villa de Elig quam alibi ubicumque quam diu vixeritis absque metu et alicuius pene incursu dicta arte phisice uti possitis".

Se les exime, igualmente, de cualquier tipo de órdenes, prohibiciones, sanciones, etc. que pudieran obrar en su contra, puesto que han sido aprobados en el arte que ejercen, y se ordena a los oficiales del Reino de Valencia, gobernador, justicia, bailes, etc. que respeten al poseedor de la licencia dejándole practicar libremente en los lugares de su jurisdicción so pena de incurrir en la «ira e indignación» regia, teniendo que pagar en caso de contravenir dicho mandato, mil florines de oro aplicables al erario real.

Se recomienda, por fin, al nuevo médico o cirujano, ejercer su profesión con pleno derecho y exigir a los demás que se la respeten, tal como le ha sido reconocido por la autoridad competente:

«Teneant (vobis) firmiter et observent tenerique et observari faciant et non contraveniant aut aliquem contravenire permittant alique ratione seu causa" (6).

\subsection{Licencia concedida por el Justicia Civil de Valencia}

El formulario de este tipo de licencias es radicalmente distinto a las anteriores. La que vamos a estudiar se refiere al permiso que el Justicia Civil de Valencia, Johan de Vilarasa, concedió el 17 de febrero de 1413 a Bernat Prats, de Concentaina, para ejercer la cirugía (7).

Comienza el documento dando fe de que el interesado, Bernat Prats, ha entregado al Justicia la carta de los examinadores municipales en que 
acreditan su comparecencia y superación de la prueba a que le sometieron.

Inserta dicha misiva en el mismo texto, su contenido, a grandes rasgos, es el siguiente:

La carta está fechada el 15 de febrero de 1413 y tiene como emisores a los examinadores oficiales de médicos y cirujanos de la ciudad de Valencia, cargo que ese año, según consta en el texto, ostentan Berthomeu Urgelles y Vicent Loret (8):

"...de nós, mestre Berthomeu Urgelles e mestre Vicent Loret, proffesors examinadors en art de medicina, examinadors en l'any present de totes e sengles persones volents exercir e usar d'art de físicha e de cirurgia en la dita ciutat e Regne de aquella».

Está dirigida al Justicia Civil de la ciudad y se le notifica que:

«per a nosaltres es stat examinat en Bernat Prats, barber de la vila de Cocentayna, en art de cirurgia»

el qual ha sido encontrado «competent e expert» para practicarla.

Finaliza la misiva pidiendo al Justicia le otorgue licencia «de praticar de la art" y está signada por los examinadores con sus sellos particulares.

Seguidamente, se constata el juramento que el nuevo cirujano prestó ante los Evangelios, comprometiéndose a practicar «bé e lealment ... el dit art de cirurgia».

Una vez recibido éste - sigue consignándose - el Justicia concede formalmente la licencia, otorgando «plen poder" para que:

"sens encorriment d'alcuna pena usas per la dita ciutat e Regne de València de la dita art de cirurgia".

Estos hechos son notificados por el Justicia a los oficiales del reino mediante otra carta en la que a su vez inserta la de los examinadores, el juramento del interesado acerca de su correcto proceder y la licencia que le ha sido concedida, especificando, de nuevo, su campo de ejercicio con más precisión: «en la dita ciutat e en totes e qualsevol villes e lochs del Regne de aquella», anunciándoles, además, que a Bernat Prats se le ha hecho entrega de una "carta testimonial» que acredita lo dicho.

\subsection{Estudio comparativo de las licencias}

Un estudio comparativo de la limitada documentación presentada nos evidencia relaciones y diferencias de forma y contenido entre ambos tipos de documentos. 
La tipología documental muestra para las licencias reales una estructura según los apartados siguientes: intitulación, preámbulo, dirección, disposición, cláusulas finales, fecha: tópica, crónica (año de la Natividad del Señor; sistema directo) y personal y signos de validación: sello (pendiente).

Por su parte, las licencias municipales incluyen: un documento principal (doc. 1), en el que se insertan otros dos: carta de los médicos examinadores al Justicia Civil (doc. 2), y carta del Justicia Civil a los oficiales del reino (doc. 3 ).

El documento principal (doc. 1) está estructurado del modo siguiente: fecha: crónica (año de la Natividad del Señor; sistema directo), intitulación y súplica. Inserción del documento 2. Disposición (doc. 1). Cláusulas finales (doc. 1). Inserción del documento 3.

A su vez los documentos 2 y 3 tienen los siguientes apartados, similares en ambos: dirección, intitulación, disposición, fecha: tópica y crónica (año de la Natividad del Señor; sistema directo) y signos de validación: sello: de placa (doc. 2) y pendiente (doc. 3).

Detallando aún algunos aspectos formales, se constata el distinto origen de las fuentes: Real Chancillería para las primeras y Manaments y Empares para las segundas, lo que conlleva la concesión de las licencias por autoridades diversas: realeza en las de Real Cancillería y el Justicia Civil en las procedentes de Manaments y Empares.

Observamos, igualmente, examinadores con diferentes categorias socio-políticas", puesto que en las licencias reales siempre examina un médico de la casa real: "prothofísico", "prothocirujano» —en nuestro caso Gabriel García, médico de la reina doña Maria-. En las licencias municipales, son los examinadores oficiales de la ciudad quienes efectúan la prueba.

Aparece, en fin, como divergencia, el ámbito de ejercicio otorgado a cada médico en función de la autoridad de la que emana: tanto en las villas de origen como en cualquier otro lugar donde habiten, en el caso de las reales; y sólo para la ciudad y Reino de Valencia, en las municipales.

\section{ANOTACIONES FINALES}

Los datos constatados en esta lectura superficial sóló cobran significación si los englobamos en el estudio más amplio (9) acerca de las licencias como base del ejercicio médico, hecho histórico de carácter individual únicamente comprensible dentro de la sanidad como realidad perteneciente a una determinada formación social. Esto nos ayuda a responder a las anotaciones que adelantamos en la introducción.

Sabemos por otros estudios, y eso aportaría elementos para resolver el interrogante de las diversas fuentes de documentación y las diferentes autoridades que otorgan las licencias, que la licencia real suele tener 
carácter de privilegio (10), porque normalmente se refiere a casos difíciles o problemáticos para una jurisdicción ordinaria. Las licencias municipales tienen un carácter más ordinario y, como hemos visto, menor amplitud geográfica en el ejercicio.

Por casos especiales entendemos: problemas de intrusismo (11), remisión de licencias, dispensas de examen, permisos concedidos a la minoría judeo-musulmana para practicar la medicina y la cirugía, a mujeres, etc.

Conocido esto, adelantamos la hipótesis, no la comprobación, de que tras las licencias reales analizadas se oculte algún caso especial que nuestra investigación no nos ha manifestado, como: falta de algún requisito indispensable para acceder al grado de médico o cirujano (estudios, práctica junto a otro profesional), tal como estaba establecido (12), ejercicio clandestino de la profesión antes de la recepción de la licencia, etc.

Profundizando más en el significado de las licencias para el ejercicio de la medicina en la Edad Media, no creemos errar cuando les atribuimos una doble función: control social por parte de los poderes públicos y capacitación profesional. La primera, porque tanto documentos como investigación han demostrado cierto control ideológico y la exclusión del ejercicio a determinados individuos pertenecientes a grupos sociales marginados.

Respecto a la segunda, profesionalización, es fácilmente deducible, pues conocemos perfectamente tanto los esfuerzos por eliminar cualquier tipo de intrusismo, indicio de acientifismo e intromisión social, como el afán de racionalización científica que se va imponiendo en la medicina estructurando los estudios y, como hemos constatado, estableciendo exámenes para los candidatos (13).

Por supuesto, la profesionalización conlleva una cierta conciencia de clase que, en estos momentos, se observa tanto en la exigencia de unos requisitos científicos exigidos a los médicos y cirujanos como en la detentación de una serie de cargos socio-políticos en la sociedad del siglo XV, si bien la propia clase admite una jerarquía dentro de los mismos profesionales, ya que mientras unos se dedican simplemente al ejercicio de la medicina en ambientes rurales o urbanos, otros ocupan cargos políticos o tienen prerrogativas extraordinarias («desospitadors», "prothometges», médicos de hospitales) con respecto a los anteriores.

1413, febrero 17 . Valencia

Johan de Vilarasa, justicia civil de la ciudad de Valencia, concede licencia para ejercer la cirugía a Bernat Prats, vecino de Cocentaina.

A.R.V., MANAMENTS Y EMPARES (JUSTICIA CIVIL), N. ${ }^{\circ} 4$, fol. $19 \mathrm{r}^{\circ}-\mathrm{v}^{\circ}$ 
Anno a Nativitate Domini $\mathrm{M}^{\circ} \mathrm{CCCC}^{\circ} \mathrm{XII1^{ \circ }}$ die veneris XVII febroarii, davant lo honrat en Johan de Vilarasa, cavaller, justícia civil de València, comparech en Bernat Prats, de la vila de Cocentayna, la present letra següent:

«Al molt honrat mossèn Johan de Vilarasa, cavaller, justicia de la ciutat de València en lo civil, de nos, mestre Berthomeu Urgelles e mestre Vicent Loret, professors en art de medicina, examinadors en l'any present de tots e sengles persones volents exercir e usar d'art de físicha e de cirurgia en la dita ciutat e Regne de aquella. Salutem ab subjecta reverència e honor, nottificam a vestra saviesa que per nosaltres es stat examinat en Bernat Prats, barber de la vila de Cocentayna, en art de cirurgia, en la qual examinació l'avem atrobat competentment e expert a usar e praticar de la dita art de cirurgia. E per ço, que per vos li sia atorgada licencia de praticar de la art en la dita manera la present testimonial que significancia de les dites coses li havem liurada sagellada ab dos nostres sagells a clarificació vestra.

Scrit en València a XV del mes de febrero l'any de la Nativitat de Nostre Senyor $\mathrm{M}^{\circ} \mathrm{CCCC}^{\circ} \times 11^{\circ} \%$.

E presentada la dita letra tantost lo dit honrat justícia reebe sagrament del dit en Bernat Prats a Nostre Senyor Deu e als Sants Evangelis de la sua ma dreta corporalment tocats en virtut del quel diu e jura que be e lealment se hauria en praticar del dit art de cirurgia sobre la quel per los dits examinadors sia stat examinat, administrant sobre aquella segons necessitat de la cosa juxta [roto] de la preinserta letra.

$E$ [rebut] lo dit sagrament lo dit e honrat justícia atorga a aquell dit en Bernat Prats, axí examinat e plen poder e sens encorriment d'alcuna pena usas per la dita ciutat e Regne de Valencia de la dita art de cirurgia sia, segons en la dita letra preinserta es contengut. Manant como sia de totes les dites coses carta testimonial huiusmodi tenor:

"Als molts honrats universes e sengles officialș e lochtinent de senyoria tinent dins lo Regne de València, constituïts als quals les presents pervendran, e presentades seran o alcunes lochtinents:

De nos, en Johan de Vilarasa, cavaller, justícia de la ciutat de Valencia en lo civil, salutem e honor. Notifficam a vestra honrada saviesa e de cascun de nosaltres que en Bernat/[[fol. $\left.19 \mathrm{v}^{\circ}\right]$ Prats, de la vila de Cocentayna, solemnialment examinat per los honrats mestre Berthomeu Urgelles e mestre Vicent Loret, professors en medicina, examinadors en aquest any dels cirurquis, volents praticar de art de phísica e de cirurgia novellament, es stat atrobat abte, expert e sufficient e praticar de art de cirurgia tant solament, de la qual abtea e sufficiencia son certificats per los 
dits examinadors ab letra llur dos sagelles sagellada del tenor següent:

Al molt honorable imperatur totu tenor per ut supra.

Per que rebut del dit Bernat Prats sagrament a Nostre Senyor Déu e als Sants quatre Evangelis de la sua ma dreta tocats, que bé e lealment se haura e practicar del dit art de cirurgia en la forma en la preinserta letra [es stada continguda] havem aquell donada e atorgada licencia e facultat de usar e practicar del dit art de cirurgia en la dita ciutat e en totes e qualsevol villes e lochs del Regne de aquella sens encorriment de alcuna pena. En totes de les quals coses la present carta testimonial li haut manada per sagellada en pendent ab lo sagell de la cort nostra en ucets reals emprentat.

Datum Valentie XVII die febroarii anno a Nativitate Domini. Juan Carles de Rojas. $\mathrm{M}^{\circ} \mathrm{CCCC}^{\circ} \mathrm{XXII1^{ \circ }}$.

1443, abril 2 10. Valencia

La reina $D .^{a}$ María concede licencia para ejercer la Cirugia a Joan de Çamora, vecino de Cocentaina.

A.R.V., REAL CANCHILLERIA, reg. 260, fol. 130 v.

\section{LICENTIA UTENDI ARTE CIRURGIE PRO JOHANNE DE ÇAMORA}

Nos Maria etc. Quemadmodum salutis tutelam corporum vittatis imperitis et temerariis remedis procuramus sic experta et probata medicaminum ministeria curandorum languentium gratiam promovemus. Et quare vos fidelem nostrum Johanem de Çamora, ville de Cocentayna per fidelem phisicum et cirurgicum domus nostre Gabrielem Garcie magistrum in medicina examinatum ydoneum et suficientem in arte cirurgie et veridica relatione ipsius magistri Gabrielis Garcie comperimus. Tenore presentis vobis eidem Johani de Çamora concedimus et licentiam ac facultatem plenariam elargimur quod absque metu et alicuius pene incursu tam in dicta villa de Cocentayna quam alibi quam diu vixeritis dicta arte cirurgie uti positis inhibitionibus, ordinationibus prachmaticis sanctionibus seu provissionibus quibuscumque in contrarium editis sive factis et penis in eis adiectis obsistentibus nullo modo. Quem in usu et exercitio dicte artis vos dictum Johanem de Çamora huius serie aprobamus. Mandantes gerentivices gubernatori in Regno Valentie, justiciis, baiuliss ceterisque universis et singulis oficialis domini regis et nostris presentibus et futuris quatenus licentiam et concesionem nostram huiusmodi vobis te- 
neant firmiter et observent tenerique et observari faciant et non contravenerant aut aliquem contravenire permittant aliqua ratione seu causa.

In cuius rei testimonium presentem fieri iussimus regio sigillo impendenti munitam.

Datum Valentie $X^{a}$ die aprilis anno a Nativitate Domini $\mathrm{M}^{\circ} \mathrm{CCCC}^{\circ}$ $X X X X I 1 I^{\circ}$. Regnique dicte domini regis Sicilie ultra Farum anno VIIII . Aliorum nostro regnorum anno XXVIII ${ }^{\circ}$. La Reyna.

Domina regina mandavit mihi Guillelmo Bernardo de Brugada vissus per Gabrielem Garcie ad cuius relationem expresatem fuit repertus suficiens.

\section{Probata.}

\section{5, noviembre 3. Valencia}

Licencia concedida por la reina $D .^{a}$ Maria a Joan Martí vecino de Elche, para ejercer la Medicina.

A.R.V., REAL CANCILLERIA, reg. 261, fol. $148 r^{\circ}-v^{\circ}$.

\section{LICENTIA UTENDI ARTE FISICE PRO JOHANNE MARTI VILLE D'ELIG}

Nos Maria etc. Quemadmodum salutis tutelam corporum vicatis imperitis et temerariis remediis procuramus sic experta et probata medicaminum ministeria curandorum languentium gratia promovemus. Et quia vos fidelem nostrum Johannem Marti habitatorem ville de Elig per fidelem nostrum Gabrielem Garcia magistrum in artibus et medicina fisicum et cirurgicum domus nostre mandato nostro examinatum ydoneum et sufficientem in arte fisice ex veridica relatione ipsius magistri Gabrielis Garcie comperimus. Tenore presentis vobis eidem Johanni Marti concedimus et licentiam ac facultatem plenariam elargimur quod tam in dicta villa de Elig quam alibi ubicumque quam diu vixeritis absque metu et alicuius pene incursu dicta arte phisice uti possitis inhibitionibus ordinationibus pracmaticis sanctionibus privilegiis et seu provisionibus quibuscumque in contrarium editis sive factis et penis in eis adiectis obsistentibus ullo modo quoniam in usu et exercitio dicte artis phisice vos huius serie approbamus. Mandantes per presentes gerentivices gubernatoris in Regno Valentie. Necnon justiciis, baiulis, procuratoribus, juratis dicte ville de Elig ceterisque universis et singulis officialibus et subditis dicti domini regis et nostris presentibus et futuris ubi libet jurisdictionem exercentibus et locatenentibus eorundem de certa scientia et expresse per prima et secunda iussionibus sub incursu regie ad nostre ac nostre indignationis 
et ire penaque mille florenorum auri a bonis cuiuslibet contrafacientis exigendorum regioque applicandorum erario quatenus licentiam aprobationem et conesionem nostras huiusmodi vobis dicto Johanni Marti teneant firmiter et observent tenerique et observari faciant et non contraveniant aut aliquem contravenire permittant alique ratione seu causa [fol. $148 \mathrm{v}^{\circ}$.]

In cuius rei testimonium presentem fieri iussimus regio sigillo inpendenti munitum.

Datum Valentie tercia die novembris anno a Nativitate Domini $M^{\circ}$

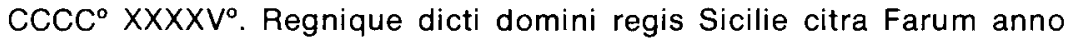
undecimo aliorum vestro regnorum anno tricesimo. La Reyna.

Franciscus Çes Cases mandato regio facto ad ibidem Gabrielis Garsie prothomedici domus dicta domine regine qui hanc vidit et examinatus fuit repertus sufficiens.

Probata. Pastor.

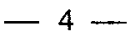

1445, diciembre 3 . Valencia

Licencia para ejercer la cirugia concedida por la reina $D .^{a}$ Maria a Joan Gonzálvez, vecino de Elche.

A.R.V., REAL CANCILLERIA, reg. 260 , fol. 170 v.

\section{CIRURGIE PRO JOHANNE GONZALVEZ VILLE D'ELIG}

Nos Maria etc. Quemadmodum salutis tutelam corporum vicatis imperitis et temerariis remediis procuramus sic experta et probata medicaminum ministeria merendorum languentium gratia promovemus. Et quia vos fidelem nostrum Johannem Gonąlvez barbitonsorum ville de Elig per fidelem fisicum et cirurgicum domus nostre magistrum Gabrielem Garcia examinatum ydoneum et suficientem in arte cirurgie exercenda informatione ipsius magistri Gabrielis comperimus. Tenore presentis vobis eidem Johanni Gonzalvez concedimus et licentiam ac facultatem plenariam elargimur quod absue metu alicuius pene incursu tam in dicta villa de Elig quam alibi ubicumque dicta arte cirurgie uti possitis et valeatis cum vixeritis inhibitionibus ordinationibus pracmaticis sanctionibus et seu provisionibus quibuscumque in contrarium editis sive factis et penis in eis adiectis obsistentibus nullo modo quem in uso et exercitio dicte artis cirurgie vos dictum johannem huiusmodi serie aprobamus. Mandantes gubernatori Regni Valentie nenon justiciis juratis baiulis procuratoribus 
ceterisque officialibus regiis et nostris presentibus et futuris ad quos spectet et locatis eorumdem de certa scientia et expresse sub incursu regie ac nostre indignationie et ire penaque mille florenorum auri regio applicandorum erario quatenus licentiam approbationem et concessionem nostras huiusmodi vobis dicte Johanni teneant firmiter et observent tenerique et observari faciant inviolabiliter per quoscumque et non contraveniant aut aliquem contravenire permitant aliqua ratione seu causa.

In cuius rei testimonium presentem fieri iussimus regio sigillo in pendenti munitum.

Datum Valentie die tercia decembris anno a Nativitate Domini

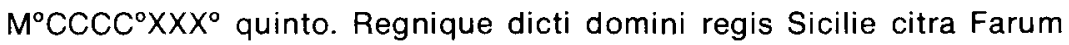
anno undecimo aliorum vero regnorum anno tricesimo. La Reyna.

Franciscus Cescases mandato regio facto ad relationem Gabrielis Garcie prothomedici domus dicte domine Regine qui hanc vidit ipsumque examinavit.

Probata. Pastor. 


\section{NOTAS}

(1) GALLENT MARCO, M. (1980), La asistencia sanitaria en Valencia (1400-1512), tesis doctoral inédita, 2 vols., Valencia.

(2) MAZZI, M.* S. (1978), Salute e societa nel Medioevo, Ed. La Nuova Italia, Florencia, pág. 3.

(3) GALLENT MARCO, M. (1980), vol. I, págs. 300-416. GALLENT MARCO, M. (1983), Profesionalización y control social del personal médico en el siglo XV: la licencia para ejercer del cirujano Johan Pasuyal de Algemesi, en Saitabi, vol. XXXIII, peggs. 99-103.

(4) A.R.V. REAL CANCILLERIA, reg. 260, fol. $130 \vee^{\circ}$ y $170 \vee$; reg. 261 , fol. i48 $r^{\circ}-v^{\circ}$.

(5) AR.V. REAL CANCILLERIA, reg. 261, fol. 148 r $\mathrm{r}^{\circ}$.

(6) Cfr. nota 5

(7) AR.V. MANAMENTS Y EMPARES (JUSTICIA CIVIL), N. ${ }^{\circ} 4$ (1413), última mano, fol. $19 \mathrm{r}^{\circ}-\mathrm{v}^{\circ}$

(8) En el texto aparecen como examinadores Berthomeu Urgelles y Vicent Loret, pero al revisar los nombramientos constatados en los Manual de Conselis, que se efectúan siempre el 22 de diciembre de cada año, los correspondientes a 1412 para actuar durante el año siguiente, no coinciden con los médicos citados. Según esta fuente, durante el año 1413 desempeñaron el cargo de examinadores municipales Luis d'Ordis y Jacme Roig (M.C. (A-25), fol. 123 r. A.M.V.). Vicent Loret y Berthomeu Urgelles lo ocuparon el año anterior, 1412 (M.C. (A-24), fol. 426 r. ${ }^{\circ}$ A.M.V.). El error del documento que hemos estudiado tal vez sea imputable al escribano, aunque no podemos darlo por seguro puesto que no poseemos la carta original de los examinadores en la que se constatan sus nombres.

(9) GALLENT MARCO, M. (1980), vol. I, pág. 348-366.

(10) RODRIGO PERTEGAS, J. (1902), Recuerdo apologético del maestro en Medicina Domingo Ros de Ursins, Valencia, pág. 18-20.

(11) GALLENT MARCO, M. (1981), Sobre intrusismo médico en Valencia (siglo XV), Comunicación presentada en el I// Congres d'Historia de la Medicina Catalana (Lérida) (en prensa).

(12) GALLENT MARCO, M. (1980), vol. I, pág. 305-311.

(13) GALLENT MARCO, M., El gremi de metges i cirurgians de Valencia: procés de constitució (1310-1499)", en L'Espill (en prensa). 